\section{Epidural Hematoma}

Beth Rush

Psychiatry and Psychology, Mayo Clinic, Jacksonville, FL, USA

\section{Synonyms}

\section{$\mathrm{EDH}$}

\section{Definition}

Epidural hematoma is a traumatic accumulation of blood that forms following blunt force on the head (i.e., baseball bat, hammer). The force of impact is strong enough to tear the dural cover of the brain from the skull. This tearing of the dural cover disrupts the nearby arteries and veins, as well as dural branches of these blood vessels. One of the most common sites for epidural hematoma is the temporoparietal area due to skull fracture disrupting the middle meningeal artery or its dural branches. Motor vehicle accidents and physical assaults are common causes of epidural hematoma. Frequently neurosurgical intervention is required on an emergent basis to prevent an increase in intracranial pressure from rapidly accumulating blood. If intracranial pressure elevates too quickly or too high, the patient can become comatose. Most commonly, craniotomy with evacuation is used to intervene in cases of epidural hematoma. On some occasions, an epidural drain is placed to assist in the funneling off of extra fluid from the surface of the brain.

\section{Cross-References}

- Cerebral Hemorrhage

- Skull Fracture

\section{References and Readings}

Ammerman, J. M., Jarrell, S. T., \& Polin, R. S. (2006). Traumatic intracranial hemorrhage. In R. W. Evans (Ed.), Neurology and trauma (2nd ed., pp. 156-166). New York: Oxford University Press. 